\title{
Extracardiac conduit versus lateral tunnel cavopulmonary connections at a single institution: Impact on outcomes
}

\author{
Anthony Azakie, MDa \\ Brian W. McCrindle, MD, FRCP(C) ${ }^{b}$ \\ Glen Van Arsdell, MDa \\ Lee N. Benson, MD, FRCP(C) ${ }^{b}$ \\ John Coles, MDa \\ Robert Hamilton, MD, FRCP(C $)^{b}$ \\ Robert M. Freedom, MD, FRCP(C) ${ }^{b}$ \\ William G. Williams, MDa
}

From the Departments of Surgery and Pediatrics, Divisions of Cardiovascular Surgery a and Cardiology, ${ }^{\mathrm{b}}$ the Hospital for Sick Children, University of Toronto School of Medicine, Toronto, Ontario, Canada.

Received for publication Sept 14, 2000; revisions requested Feb 27, 2001; revisions received April 24, 2001; accepted for publication April 27, 2001.

Address for reprints: William G. Williams, MD, Division of Cardiovascular Surgery, Hospital for Sick Children, 555 University Ave, Rm 1525, Toronto, Ontario M5G $1 \mathrm{X} 8$, Canada.

J Thorac Cardiovasc Surg 2001;122:1219-28

Copyright @ $\odot 2001$ by The American Association for Thoracic Surgery

0022-5223/2001 $\$ 35.00+0 \quad \mathbf{1 2 / 1 / 1 1 6 9 4 7}$

doi:10.1067/mtc.2001.116947
Objective: To compare outcomes of extracardiac conduit and lateral tunnel Fontan connections in a single institution over a concurrent time period.

Methods: Between January 1994 and September 1998, 60 extracardiac conduit and 47 lateral tunnel total cavopulmonary connections were performed. Age, sex, and weight did not differ between the 2 groups. Compared with the lateral tunnel group (LT group), patients undergoing the extracardiac conduit procedure (EC group) had a trend to a higher incidence of morphologically right ventricle (EC group $48 \%$ vs LT group $32 \% ; P<.09$ ), a higher incidence of isomerism/heterotaxy syndrome (EC $22 \%$ vs LT $0 \% ; P<.001$ ), worse atrioventricular valve regurgitation (EC $11 \%$ moderate-plus vs LT 0\%; $P<.06$ ), and lower McGoon indices (EC $1.8 \pm 0.5$ vs LT 2.1 $\pm 0.5 ; P<.03)$. Preoperative arrhythmias, transpulmonary gradients, room air oxygen saturations, ejection fractions, ventricular end-diastolic pressure, and pulmonary artery distortion did not differ between groups. Cardiopulmonary bypass times and fenestration usage were similar in both groups.

Results: Overall operative mortality was $5.6 \%$ and did not differ between groups. The LT group had a significantly higher incidence of postoperative sinoatrial node dysfunction $(45 \%$ vs EC group $15 \% ; P<.007)$, supraventricular tachycardia $(33 \%$ vs EC group $8 \% ; P<.0009)$, and need for temporary postoperative pacing $(32 \%$ vs $12 \% ; P<.01)$. Median duration of intensive care unit stay (EC 2 days, range 1-10 days, vs LT 2.8 days, range $1-103$ days; $P<.07$ ) and ventilatory support (EC 1 day, range $0.25-10$ days, vs LT 1 day, range 0.25-99 days; $P<.03$ ) were all longer in the LT group. Median chest tube drainage (EC 8 days, LT 9 days) was similar in both groups. Follow-up averaged $2.5 \pm 1.4$ years in the EC group and $2.8 \pm 1.9$ years in the LT group. There were 2 late deaths. Overall survival is $94 \%$ at 1 month, $92 \%$ at 1 year, and $92 \%$ at 5 years. Late ejection fraction or atrioventricular valve function did not differ between groups. Intermediate follow-up Holter analysis showed a higher incidence of atrial arrhythmias in the LT group ( $23 \%$ vs $7 \% ; P<.02$ ). Multivariable analysis showed that (1) prolonged cardiopulmonary bypass time was the only independent predictor for perioperative mortality, prolonged ventilation and intensive care unit length of stay, and increased time to final removal of chest tube drains and (2) lateral tunnel Fontan connection is an independent predictor of early postoperative and intermediate atrial arrhythmias.

Conclusions: Although patients in the EC group were at higher preoperative risk, their outcomes were comparable with those of the LT group. Use of the extracardiac conduit technique for the modified Fontan operation reduces the risk of early and midterm atrial arrhythmia. 


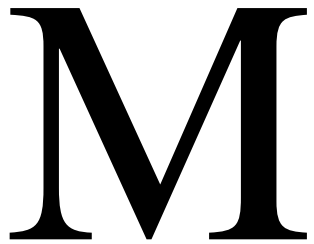

odifications of the Fontan operation have been developed to optimize the early and long-term outcomes of patients undergoing palliation for single ventricle physiology. ${ }^{1-6}$ Optimization of outcomes in part requires the construction of a Fontan circuit with optimal flow dynamics and preservation of ventricular and pulmonary vascular function, factors that can be influenced by operative techniques. Two currently favored approaches to the modified Fontan operation include either the extracardiac conduit (EC) or lateral tunnel (LT) techniques. ${ }^{6-9}$ The EC technique allows for optimal flow dynamics and preservation of ventricular and pulmonary function because the technique can be performed with minimal or no cardiopulmonary bypass (CPB) and/or limited cardioplegic cardiac arrest. In addition, the EC technique avoids sinus node manipulation, suture loading of the atrium, and atrial distention, theoretically minimizing the risk of postoperative atrial arrhythmias. ${ }^{6,7}$ Experience with the LT approach has been extensive and represents the current standard of care given the excellent outcomes with that approach. ${ }^{8,9}$ Compared with the LT circuit, the EC cannot grow and potential future reoperations may be associated with significant morbidity and mortality. In addition, the prosthetic material may predispose the patient with a single ventricle to an already increased risk of thromboembolic complications.

At the Hospital for Sick Children, University of Toronto, where more than 600 Fontan operations have been performed, the EC technique has been used in parallel with LT connections since 1994. In the current study, early and midterm outcomes of the EC and LT approaches during the same era are directly compared to determine the benefits of one procedure versus the other.

\section{Patients and Methods}

Permission to perform the Health Record review was obtained from the Research Ethics Board, the Hospital for Sick Children. Between July 1994 and September 1998, 60 patients received an EC and 47 patients received an LT cavopulmonary connection. The records of these 107 patients were reviewed for demographic, operative, and perioperative features, as well as midterm follow-up echocardiographic, Holter electrocardiographic, catheterization, and clinical data. Supraventricular tachyarrhythmias are defined as recurrent runs of more than 3 beats, symptomatic, clinically important, or sustained ( $>30$ seconds). Sinoatrial node dysfunction is defined as relative bradycardia for age, presence of sinus pause or arrest, or junctional escape rhythm. During the same period, right atrialpulmonary artery connections, external in situ pericardial tunnel connections, or Fontan procedures performed in patients over 18 years of age were not included in the analysis $(n=21)$. Preoperative demographics, morphologic features, and echocardiographic/cardiac catheterization data are summarized in Table 1. Patient age, sex, and weight did not differ between groups. Patients undergoing the EC procedure had a trend to a higher incidence of morphologically right ventricle (EC 48\% vs LT 32\%; $P=.09$ ) and a higher incidence of isomerism/heterotaxy syndromes (EC $22 \%$ vs LT $0 \% ; P=$ .001). Although patients in the LT group had higher preoperative mean pulmonary artery $(11 \pm 2$ vs $10 \pm 2 \mathrm{~mm} \mathrm{Hg})$ and pulmonary venous atrial pressures ( $6 \pm 2$ vs $5 \pm 2 \mathrm{~mm} \mathrm{Hg}$ ), the magnitude of the difference was minimal. Patients in the EC group had worse atrioventricular valve regurgitation (11\% moderate-plus vs LT $0 \%$; $P=.06)$ and lower McGoon indices $(1.8 \pm 0.5$ vs LT $2.1 \pm 0.5 ; P=$ $.03)$. The 2 groups did not differ with respect to transpulmonary gradients, room air oxygen saturations, ventricular end-diastolic pressures, Nakata index, degree of pulmonary artery distortion, ejection fraction, or preoperative arrhythmias. Previous procedures are summarized in Table 2. There was a trend toward an earlier median age for bidirectional cavopulmonary anastomosis in the EC compared with the LT group (EC 9 months, range 3-48 months; LT 10 months, range 3-156 months; $P=.09$ ). One patient in each group did not receive a staged bidirectional cavopulmonary anastomosis.

\section{Operative Techniques}

Operative data and concomitant procedures are summarized in Table 3. The decision to use either the LT or EC technique was based primarily on surgeon preference. Standard CPB techniques, including bicaval cannulation, mild hypothermia, and normocalcemic primes (in cases without cardioplegic arrest), were used. All systemic-pulmonary artery shunts were controlled before the institution of CPB. When aortic crossclamping was used, myocardial preservation included cold blood antegrade cardioplegia. With the LT technique, a semicylindrical polytetrafluoroethylene (PTFE) baffle $^{*}$ is anastomosed initially to the inferior vena cava. The suture line is carried anterior to the atrial septum to avoid pulmonary venous obstruction. Cephalad, the crista terminalis is avoided or, in the case of extensive right atrial trabeculations, superficial bites are taken at the smooth portion of the inner sinoatrial junction. When the EC technique is used, care is taken to avoid injury to the coronary sinus when the inferior cavoatrial junction is divided. Either an aortic homograft $(n=39)$ or PTFE tube $(\mathrm{n}=21)$ was used as the external conduit. The average conduit size was $20 \pm 2 \mathrm{~mm}$ (median $20 \mathrm{~mm}$, range 16-27 mm). A fenestration was used in $46(77 \%)$ patients receiving an EC and in 40 (85\%) patients receiving an LT connection. The median size of the fenestration was $4 \mathrm{~mm}$ (range $3.5-5 \mathrm{~mm}$ ). Although we currently perform the EC Fontan operation without CPB in certain cases, $\mathrm{CPB}$ was used in all cases reported in this study. The median CPB times (EC 102 minutes, range 59-306 minutes; LT 109 minutes, range 62-289 minutes; $P=.29$ ) did not differ between groups. Aortic crossclamping was used in $15 \%$ of patients in the EC group. Associated intracardiac procedures were performed in one third of patients in the LT group $(P=.16)$ compared with one fifth of patients in the EC group (Table 3). Pulmonary artery augmentation was performed in most patients in both groups (EC 60\%, LT 55\%).

\section{Data Analysis}

Data are described as frequencies, medians with ranges, and means with standard deviations as appropriate. In cases in which data are

*Gore-Tex; registered trade mark of W. L. Gore \& Associates, Inc, Flagstaff, Ariz. 
TABLE 1. Preoperative demographics, morphologic features, and echocardiographic/cardiac catheterization data

\begin{tabular}{|c|c|c|c|c|c|}
\hline & EC & $\mathbf{n}$ & LT & $\mathbf{n}$ & $P$ value \\
\hline \multicolumn{6}{|l|}{ Demographics } \\
\hline \multicolumn{6}{|l|}{ Age (y) } \\
\hline Mean & $3.8 \pm 2.25$ & 60 & $4.0 \pm 3.0$ & 47 & \\
\hline Median & $2.9(1.7-12.0)$ & & $2.7(1.3-14.2)$ & & .46 \\
\hline \multicolumn{6}{|l|}{ Sex } \\
\hline Male & 37 & & 30 & & .82 \\
\hline Female & $23(23 \%)$ & & $17(36 \%)$ & & \\
\hline \multicolumn{6}{|l|}{ Weight (kg) } \\
\hline Mean & $14.9 \pm 5.2$ & & $15.9 \pm 9.1$ & & \\
\hline Median & $13.2(9.3-35)$ & 60 & $13(8.3-62.8)$ & 47 & .90 \\
\hline BSA, mean $\left(m^{2}\right)$ & $0.57 \pm 0.12$ & 60 & $0.6 \pm 0.2$ & 47 & .30 \\
\hline \multicolumn{6}{|l|}{ Morphologic features } \\
\hline Tricuspid atresia & $12(20 \%)$ & & $12(25 \%)$ & & 1.0 \\
\hline Univentricular heart & $7(11 \%)$ & & $3(6 \%)$ & & .50 \\
\hline DILV & $11(18 \%)$ & & $11(24 \%)$ & & 1.0 \\
\hline HLHS & $14(23 \%)$ & & $6(13 \%)$ & & .21 \\
\hline PA/IVS & $6(10 \%)$ & & $5(11 \%)$ & & 1.0 \\
\hline DORV & $7(11 \%)$ & & $7(15 \%)$ & & .80 \\
\hline Other & $1(2 \%)$ & & $5(10 \%)$ & & .09 \\
\hline Isomerism/heterotaxy syndrome & $13(22 \%)$ & & 0 & & $<.001$ \\
\hline Dextrocardia & $2(3 \%)$ & & $5(11 \%)$ & & .24 \\
\hline Ventricular morphology & & & & & .09 \\
\hline Left ventricle & $31(52 \%)$ & & $32(68 \%)$ & & \\
\hline Right ventricle & $29(48 \%)$ & & $15(32 \%)$ & & \\
\hline \multicolumn{6}{|l|}{ Preoperative data } \\
\hline Systolic blood pressure, mean (mm Hg) & $87 \pm 12$ & 59 & $87 \pm 10$ & 47 & .85 \\
\hline Pulmonary artery pressure, mean $(\mathrm{mm} \mathrm{Hg})$ & $10 \pm 2$ & 60 & $11 \pm 2$ & 47 & .05 \\
\hline Atrial pressure, mean $(\mathrm{mm} \mathrm{Hg})$ & $5 \pm 2$ & 56 & $6 \pm 2$ & 44 & .01 \\
\hline Transpulmonary gradient, mean $(\mathrm{mm} \mathrm{Hg})$ & $5 \pm 2$ & 55 & $5 \pm 2$ & 43 & .86 \\
\hline Room air oxygen saturation (\%) & $82 \pm 4$ & 54 & $83 \pm 5$ & 40 & .16 \\
\hline Ventricular EDP, mean (mm Hg) & $7 \pm 3$ & 59 & $7 \pm 2$ & 45 & .41 \\
\hline Pulmonary artery distortion & $20(40 \%)$ & & $14(37 \%)$ & & .71 \\
\hline \multicolumn{6}{|l|}{ Preop AV valve regurgitation } \\
\hline None-trace & $30(56 \%)$ & 60 & $33(71 \%)$ & 46 & \\
\hline Mild & $23(38 \%)$ & & $13(28 \%)$ & & Trend \\
\hline Moderate & $7(11 \%)$ & & 0 & & $<.001$ \\
\hline McGoon index, mean & $1.8 \pm 0.5$ & 57 & $2.1 \pm 0.5$ & 39 & .03 \\
\hline Nakata index, mean & $264 \pm 132$ & 56 & $275 \pm 115$ & 40 & .68 \\
\hline Ejection fraction, mean $(\%)$ & $61 \pm 8$ & 58 & $63 \pm 10$ & 43 & .34 \\
\hline Arrhythmia & & & & & 1.0 \\
\hline None & $53(90 \%)$ & & $43(93 \%)$ & & \\
\hline Junctional & $4(7 \%)$ & & $2(4 \%)$ & & \\
\hline Pacer & $2(3 \%)$ & & $1(3 \%)$ & & \\
\hline
\end{tabular}

$E C$, Extracardiac conduit; $L T$, lateral tunnel; $B S A$, body surface area; DILV, double-inlet left ventricle; $H L H S$, hypoplastic left heart syndrome; $P A / I V S$, pulmonary atresia/intact ventricular septum; $D O R V$, double-outlet right ventricle; $E D P$, end-diastolic pressure; $A V$, atrioventricular.

missing, the number of nonmissing values is given. Characteristics and outcomes of patients having LT versus EC Fontan connections were compared by means of the Fisher exact tests, $\chi^{2}$ tests, MantelHaenszel $\chi^{2}$ tests, $t$ tests, and Kruskal-Wallis analysis of variance as appropriate. Independent factors associated with postoperative arrhythmias during hospital admission were sought with the use of multiple logistic regression analysis. Independent factors associ- ated with length of postoperative stay in the intensive care unit (ICU) and the hospital, duration of mechanical ventilation, and duration of chest tube drainage were sought with the use of Cox proportional hazard regression modeling with the deaths occurring before the studied event being censored. Independent factors associated with the presence of postoperative ascites, defined as either need for insertion of a peritoneal drainage 
TABLE 2. Previous procedures

\begin{tabular}{|c|c|c|c|c|c|}
\hline Previous procedures & EC & $\mathbf{n}$ & LT & $\mathbf{n}$ & $P$ value \\
\hline Bidirectional cavopulmonary anastomosis & & 59 & & 44 & 1.0 \\
\hline None & 1 & & 1 & & \\
\hline Right SVC-PA & 50 & & 43 & & \\
\hline Bilateral & 3 & & 0 & & \\
\hline Kawashima & 6 & & 2 & & \\
\hline Hemi-Fontan & 0 & & 1 & & \\
\hline $\mathrm{AV}$ valve replacement & 1 & & 0 & & 1.0 \\
\hline Coarctation repair & 12 & & 4 & & .19 \\
\hline Subaortic stenosis resection & 5 & & 4 & & 1.0 \\
\hline Divide main pulmonary artery & 36 & & 20 & & .08 \\
\hline Pulmonary artery reconstruction & 26 & & 16 & & .24 \\
\hline Pulmonary artery band & 10 & & 6 & & .58 \\
\hline Coil venous collaterals & 3 & & 2 & & 1.0 \\
\hline Coil AP collaterals & 5 & & 2 & & 1.0 \\
\hline Atrial septectomy & 29 & & 18 & & .36 \\
\hline Modified Norwood procedure & 24 & & 10 & & .06 \\
\hline Systemic-pulmonary arterial anastomosis & 46 & & 34 & & .63 \\
\hline Pacemaker insertion & 2 & & 1 & & 1.0 \\
\hline
\end{tabular}

$E C$, Extracardiac conduit; $L T$, lateral tunnel; $S V C-P A$, superior vena cava-pulmonary artery; $A V$, atrioventricular; $A P$, arteriopulmonary.

TABLE 3. Operative data

\begin{tabular}{|c|c|c|c|c|c|}
\hline Operative data & EC & $\mathbf{n}$ & LT & n & $P$ value \\
\hline CPB median time (min) & $102(59-306)$ & & $109(62-289)$ & & .29 \\
\hline Aortic crossclamp, n (\%) & $9(15 \%)$ & & $47(100 \%)$ & & .001 \\
\hline Median time (min) & $29(11-105)$ & 9 & $50(22-135)$ & 47 & .15 \\
\hline Fenestration, $\mathrm{n}(\%)$ & $46(77 \%)$ & & $40(85 \%)$ & & .20 \\
\hline Mean size (mm) & $4.2 \pm 0.4$ & & $3.9 \pm 0.3$ & & $<.001$ \\
\hline \multicolumn{6}{|l|}{ Concomitant procedures } \\
\hline Intracardiac & $13(22 \%)$ & & $16(34 \%)$ & & .16 \\
\hline $\mathrm{AV}$ valve repair & 2 & & 3 & & \\
\hline Resect subaortic stenosis & 7 & & 7 & & \\
\hline Enlarge ASD & 5 & & 11 & & .03 \\
\hline Extracardiac & $40(67 \%)$ & & $29(62 \%)$ & & .60 \\
\hline Pulmonary artery augmentation & $36(60 \%)$ & & $26(55 \%)$ & & \\
\hline Bidirectional cavopulmonary anastomosis & 1 & & 1 & & \\
\hline Other & 5 & & 4 & & \\
\hline
\end{tabular}

$E C$, Extracardiac conduit; $L T$, lateral tunnel; $C P B$, cardiopulmonary bypass; $A V$, atrioventricular; $A S D$, atrial septal defect.

TABLE 4. Early outcomes

\begin{tabular}{lccc}
\hline Morbidity and mortality & EC & LT & P value \\
\hline Hospital mortality & 4 & 2 & 1.0 \\
Fontan takedown & 1 & 1 & 1.0 \\
Baffle leak & 0 & 2 & .23 \\
Thrombus & 0 & 2 & .20 \\
Chylous effusion & 7 & 4 & .60 \\
Thoracic duct ligation & & & .40 \\
Ascites & 4 & 10 & .04 \\
Bleeding/tamponade & 1 & 2 & .40 \\
Intervention (catheterization, reoperation) & 7 & 3 & .50
\end{tabular}

$E C$, Extracardiac conduit; $L T$, lateral tunnel. catheter in the ICU or prolonged drainage for more than 3 days from a catheter inserted at the time of Fontan operation, and death before hospital discharge were sought by means of multiple logistic regression analysis. Time-dependent analysis of overall survival was calculated by means of Kaplan-Meier estimates. ${ }^{10}$ Independent factors associated with the presence of atrial arrhythmias during intermediate follow-up in hospital survivors were sought by means of multiple logistic regression analysis. The variables assessed as predictors of the above outcomes measures include age, sex, weight, body surface area, date of Fontan procedure, morphologic diagnosis, ventricular morphologic characteristics, type of Fontan connection, concomitant intracardiac procedures, use of fenestration, CPB time, need for and duration of aortic crossclamping, 
TABLE 5. Postoperative arrhythmias

\begin{tabular}{|c|c|c|c|c|c|}
\hline Postoperative arrhythmias & EC & $\mathbf{n}$ & LT & $\mathbf{n}$ & $P$ value \\
\hline Temporary pacing & $7(12 \%)$ & 59 & $15(32 \%)$ & 47 & .01 \\
\hline Junctional & $9(15 \%)$ & 60 & $21(45 \%)$ & 47 & $<.001$ \\
\hline Supraventricular tachycardia & & 60 & & 47 & \\
\hline None & 55 & & 31 & & \\
\hline Atrial flutter & 1 & & 6 & & \\
\hline Junctional ectopic tachycardia & 3 & & 10 & & \\
\hline Atrial ectopic tachycardia & 1 & & 0 & & \\
\hline Any supraventricular tachycardia & $5(8 \%)$ & & $16(33 \%)$ & & $<.001$ \\
\hline
\end{tabular}

$E C$, Extracardiac conduit; $L T$, lateral tunnel.

need for pulmonary artery augmentation, age at which the bidirectional cavopulmonary anastomosis was performed, and need for coiling aortopulmonary collaterals or venous collaterals. Other preoperative predictors used in the analysis include mean pulmonary artery pressure, atrial pressure, transpulmonary pressure gradient, room air oxygen saturations, ventricular end-diastolic pressure, pulmonary artery distortion, preoperative arrhythmias, presence of atrioventricular valve regurgitation, McGoon index, Nakata index, and ejection fraction. All analyses were performed with the use of SAS statistical software version 7 (SAS Institute, Inc, Cary, NC) using default settings.

\section{Results}

\section{Early Morbidity and Mortality (Table 4)}

Overall operative mortality was $5.6 \%(\mathrm{n}=6$ patients, $\mathrm{EC}=$ 4 patients, LT $=2$ patients). The first patient died of low output state after creation of a 21-mm homograft EC Fontan connection. A 4-mm fenestration was used. Preoperatively, the patient had small pulmonary arteries and an ejection fraction of $40 \%$. The second patient died of Staphylococcus/ Hemophilus sepsis 15 days after creation of a 23-mm aortic homograft EC Fontan connection. The third patient underwent a fenestrated 23-mm aortic homograft EC Fontan operation in the setting of right atrial isomerism and a complex double-outlet right ventricle. The patient had massive fluid losses and a Fontan takedown was performed on the second postoperative day. The patient died on the sixth postoperative day in a low output state. The fourth patient had right atrial isomerism and a double-outlet right ventricle. During placement of a 22-mm PTFE external conduit, the patient required repair of a regurgitant atrioventricular valve and anomalously draining pulmonary veins. The patient died on the tenth postoperative day of cardiac failure after takedown of the Fontan circuit. Two patients in the LT group died postoperatively. The first patient had a preoperative ejection fraction of $35 \%$ and small pulmonary arteries. After a fenestrated LT Fontan operation, his course was complicated by a prolonged junctional ectopic tachycardia, low output state, and pulmonary hemorrhage. He died 7 days postoperatively. The second patient died of ventricular failure 8 days after an LT Fontan operation. From multiple logistic regression, the only significant independent factor associated with hospital death or Fontan failure was longer duration of CPB (odds ratio [OR] 1.63 per 25-minute increment, 95\% confidence interval $[\mathrm{CI}] 1.20-2.26 ; P=.003$ ). After controlling for this variable, no other variable was significantly associated with hospital death or Fontan failure.

Fontan takedown was necessary in 2 additional patients: the first patient had complex double-outlet right ventricle with moderate atrioventricular valve regurgitation and small pulmonary arteries. A low cardiac output state developed after an EC Fontan connection was constructed. The patient recovered after takedown of the Fontan circuit. The second patient had elevated pulmonary artery pressures and small distal pulmonary arteries. Takedown was performed after failure of an LT Fontan conduit. Postoperative complications are summarized in Tables 4 and 5.

\section{Postoperative Arrhythmias (Table 5)}

The LT group had a higher incidence of postoperative sinoatrial node dysfunction (LT $45 \%$ vs EC $15 \% ; P<.001$ ). Supraventricular tachyarrhythmias also occurred more frequently in the LT group (LT 33\% vs EC $8 \% ; P<.001$ ). In $32 \%$ of patients in the LT group, temporary pacing was required in the postoperative period, compared with $12 \%$ of patients in the EC group $(P=.01)$.

By multiple logistic regression analysis of the entire cohort, LT Fontan connection was the only independent predictor of early postoperative atrial arrhythmias. From multiple logistic regression, the only significant independent factor associated with an increased need for postoperative temporary pacing was LT Fontan connection (OR 3.55 vs EC connection; 95\% CI 1.31-9.63; $P=.011)$. After controlling for this variable, no other variable was significantly associated with need for temporary postoperative pacing.

From multiple logistic regression, the only significant independent factor associated with occurrence of postoperative junctional rhythm was LT Fontan connection (OR 4.58 vs EC connection; 95\% CI 1.84-11.4; $P=.002)$. After controlling for this variable, no other variable was significantly associated with occurrence of junctional rhythm. 
TABLE 6. Postoperative data

\begin{tabular}{|c|c|c|c|c|c|}
\hline Resource use & EC & n & LT & n & $P$ value \\
\hline Median ICU length of stay (d) & $2(1-10)$ & 60 & $2.8(1-103)$ & 47 & $\begin{array}{c}.07 \\
.05 \text { exclude death }\end{array}$ \\
\hline Median hospital length of stay (d) & $11(6-52)$ & 60 & $13(7-128)$ & 47 & $\begin{array}{c}.16 \\
.13 \text { exclude death }\end{array}$ \\
\hline Median duration of ventilatory support (d) & $1(0.25-10)$ & 60 & $1(0.25-99)$ & 45 & .03 \\
\hline Median No. of inotropic drugs & $1(0-3)$ & 60 & $1(0-3)$ & 45 & .84 \\
\hline Median duration of inotropic drug use (d) & $1(0-10)$ & 60 & $1(0-19)$ & 45 & .21 \\
\hline Chest tube placement (d) & $8(4-51)$ & 59 & $9(4-63)$ & 45 & .56 \\
\hline
\end{tabular}

$E C$, Extracardiac conduit; $L T$, lateral tunnel; $I C U$, intensive care unit.

TABLE 7. Postoperative data

\begin{tabular}{|c|c|c|c|c|c|}
\hline Hemodynamics & EC & $\mathbf{n}$ & LT & n & $P$ value \\
\hline Mean systolic blood pressure $(\mathrm{mm} \mathrm{Hg})$ & $81 \pm 10$ & 54 & $84 \pm 12$ & 37 & .18 \\
\hline Atrial pressure at $0-6 \mathrm{~h}$ & $5 \pm 2$ & 60 & $7 \pm 2$ & 47 & $<.001$ \\
\hline Atrial pressure at $6-12 \mathrm{~h}$ & $6 \pm 2$ & 54 & $7 \pm 2$ & 43 & .006 \\
\hline Atrial pressure at $12-24 \mathrm{~h}$ & $7 \pm 2$ & 54 & $8 \pm 3$ & 41 & .002 \\
\hline Fontan pressure at $0-6 \mathrm{~h}$ & $13 \pm 3$ & 60 & $13 \pm 2$ & 46 & .68 \\
\hline Fontan pressure at $6-12 \mathrm{~h}$ & $14 \pm 3$ & 54 & $15 \pm 3$ & 45 & .16 \\
\hline Fontan pressure at $12-24 \mathrm{~h}$ & $14 \pm 3$ & 54 & $15 \pm 4$ & 41 & .26 \\
\hline
\end{tabular}

$E C$, Extracardiac conduit; $L T$, lateral tunnel.

From multiple logistic regression, the only significant independent factor associated with occurrence of postoperative supraventricular tachycardia was LT Fontan connection (OR 5.68 vs EC connection; 95\% CI 1.90-17.0; $P=$ .002 ). After controlling for this variable, no other variable was significantly associated with occurrence of supraventricular tachycardia.

Postoperative Hemodynamics and Resource Use (Table 6) Although the magnitude of the difference was small, postoperative atrial pressures in the LT group were higher than in the EC group. Postoperative Fontan pressure and transpulmonary gradients, however, were not different between groups.

Median ICU length of stay (EC 2 days, range 1-10 days, vs LT 2.8 days, range $1-103$ days; $P=.05$ ) and duration of ventilatory support (EC 1 day, range $0.25-10$ days, vs LT 1 day, range 0.25-99 days; $P=.03$ ) were longer in the LT group. Independent factors associated with an increased time to final extubation from mechanical ventilation included only an increased duration of CPB (hazard ratio 1.14 per 25-minute increment; $95 \%$ CI 1.03-1.26; $P=.01$ ). After controlling for this variable, no other variable was significantly associated with time to final extubation.

Independent factors associated with an increased time to discharge from the ICU included only an increased duration of CPB (hazard ratio 1.14 per 25-minute incre- ment; 95\% CI 1.03-1.26; $P=.012$ ). After controlling for this variable, no other variable was significantly associated with time in the ICU.

There were no significant factors associated with time to discharge from the hospital.

Median duration of chest tube drainage (EC 8 days, LT 9 days) was similar in both groups. The use of fenestration did not affect duration of chest tube drainage. Independent factors associated with an increased time to final removal of chest tube drains included only an increased duration of CPB (hazard ratio 1.15 per 25-minute increment; 95\% CI 1.03-1.28; $P=.016)$. After controlling for this variable, no other variable was significantly associated with time to chest tube drain removal, including type of Fontan connection and use of fenestration.

From multiple logistic regression, independent factors associated with postoperative ascites as previously defined included presence of dextrocardia (OR 5.85; 95\% CI 1.11$30.9 ; P=.038)$ and higher preoperative mean pulmonary artery pressure (OR 1.31 per $1-\mathrm{mm} \mathrm{Hg}$ increment; 95\% CI 1.04-1.66; $P=.024)$. After controlling for these variables, no other variable was significantly associated with postoperative ascites.

\section{Midterm Mortality and Morbidity}

Follow-up averaged $2.5 \pm 1.4$ years in the EC group and 2.8 \pm 1.9 years in the LT group. There were 2 late deaths. One 
patient died of stroke and subsequent multisystem organ failure at the time of transcatheter fenestration closure. The other patient died suddenly of unclear causes. With up to 6 years' follow-up, survival is $94 \%$ at 1 month, $92 \%$ at 1 year, and $92 \%$ at 5 years (Figure 1). At midterm follow-up, 1 patient had a stroke 1 month after transcatheter fenestration occlusion. He had a known baffle leak through the LT Fontan connection.

Protein-losing enteropathy developed in 1 patient 5 years after a fenestrated LT Fontan operation. The patient is currently awaiting orthotopic heart transplantation.

\section{Midterm Arrhythmias}

On follow-up, Holter/electrocardiographic analysis showed a higher incidence of atrial arrhythmias in the LT group than in the EC group $(P=.02)$. Seven percent of patients in the EC group compared with $25 \%$ of patients in the LT group had sinoatrial node dysfunction, supraventricular tachyarrhythmias, or required a pacemaker. From multiple logistic regression, significant independent factors associated with atrial arrhythmias (tachycardias or loss of sinus rhythm requiring pacemaker insertion) as noted on 24-hour ambulatory electrocardiographic monitoring during follow-up of hospital survivors included the presence of atrial arrhythmias before the Fontan procedure (OR 21.9, 95\% CI 3.39$141 ; P=.002)$ and LT Fontan connection (OR 7.94; 95\% CI 1.63-38.7; $P=.011$ ). After controlling for these variables, no other variable was significantly associated with intermediate atrial arrhythmias.

Midterm follow-up echocardiographic studies showed no significant difference in ejection fraction, qualitative ventricular function, or atrioventricular valve function between groups.

\section{Discussion}

Outcomes after the Fontan procedure have improved significantly over the past 3 decades. ${ }^{1-3,5-8}$ Improvements in early survival are in part due to (1) better understanding of patientrelated risk factors and their application to patient selection, ${ }^{1-9,11}$ (2) patient preparation and optimizing staging of the Fontan procedure, ${ }^{1-3,6-9}$ and (3) procedural modifications. ${ }^{3,6-9}$ Two of the more commonly used modifications of the Fontan operation include the LT or EC connection. Arguments have been proposed by proponents of either approach as to the advantages and/or disadvantages of one strategy versus the other. Comparisons of the 2 procedures have been difficult since proponents of a given approach will generally use that reconstructive technique for Fontan completion. The literature is lacking in comparisons of the LT versus EC cavopulmonary connections. The experience at the Hospital for Sick Children has been such that both operations have been concurrently performed since 1994 and has thus allowed us to complete a direct, retrospective comparison of the EC versus LT Fontan connections within

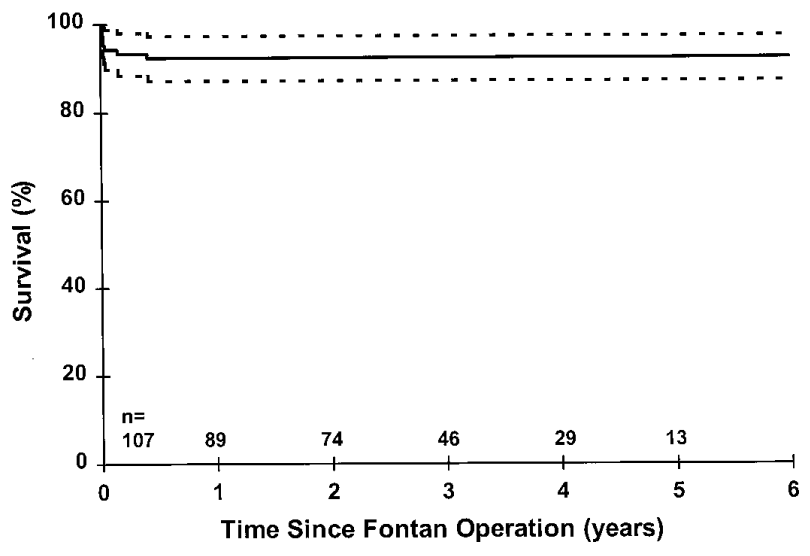

Figure 1. Kaplan-Meier survival in 107 patients undergoing palliation with an LT ( $n=47$ ) or EC ( $n=60$ ) Fontan operation. Numbers of patients at risk are given above the horizontal axis. Survival is expressed as percentage with $95 \% \mathrm{Cls}$. There is no difference in survival between patients in the LT and EC groups.

the same time period at a single institution. Our analysis suggests that the LT Fontan procedure is an independent risk factor for the development of early and midterm atrial rhythm disturbances.

\section{Limitations of the Study}

A number of biases are present in the current study. The decision to perform either an LT or EC Fontan operation was based on surgeon preference. Echocardiographic and Holter data collection was performed retrospectively by a single nonblinded examiner. The study can thus be criticized for its retrospective, nonrandomized nature. The use of a large number of predictor variables where relatively few outcome events are present is a statistical limitation of the study. A larger series with a randomized design would probably address the differences between the 2 groups more adequately.

\section{Mortality and Fontan Failure}

The hospital mortality for the entire cohort of patients was approximately 5\%. The combined mortality and Fontan failure rate (requiring takedown of the Fontan connection) in our series is approximately $7 \%$. The reported early survival after the Fontan operation has ranged from $75 \%$ to over $90 \%$ in the current era. ${ }^{1-9}$ Numerous perioperative risk factors are associated with increased early failure or mortality after the Fontan procedure. ${ }^{2,3,11}$ These include elevated pulmonary artery pressures, pulmonary artery distortion, morphologically right ventricle or isomerism/heterotaxy syndrome, severe ventricular dysfunction (or atrioventricular valve regurgitation), absence of a fenestration, and atriopulmonary connections. Other risk factors for adverse outcomes after the Fontan procedure may include the number of previous operations, absence of staging, and ventricular hypertrophy. 
TABLE 8. Midterm outcomes

\begin{tabular}{|c|c|c|c|c|c|}
\hline Midterm outcomes & EC & n & LT & n & $P$ value \\
\hline Follow-up (y) & $2.5 \pm 1.4$ & 60 & $2.7 \pm 1.9$ & 47 & .50 \\
\hline Mortality & 1 & & 1 & & 1.0 \\
\hline Stroke & 1 & & 1 & & 1.0 \\
\hline Protein-losing enteropathy & 0 & & 1 & & .44 \\
\hline Ejection fraction, mean $(\%)$ & $62 \pm 8$ & 48 & $62 \pm 7$ & 33 & .79 \\
\hline $\begin{array}{l}\text { Atrial arrhythmia } \\
\text { Junctional rhythm } \\
\text { Sinus bradycardia } \\
\text { Supraventricular tachyca } \\
\text { Pacemaker }\end{array}$ & $7(13 \%)$ & 54 & $11(25 \%)$ & 43 & .02 \\
\hline$A V$ valve function & & 44 & & 34 & \\
\hline None-trace & $23(55 \%)$ & & $20(59 \%)$ & & \\
\hline Mild & $15(32 \%)$ & & $14(41 \%)$ & & \\
\hline Mild-moderate & $6(13 \%)$ & & 0 & & .26 \\
\hline
\end{tabular}

$E C$, Extracardiac conduit; $L T$, lateral tunnel; $A V$, atrioventricular.

A direct comparison of the preoperative features of patients in the EC group versus those in the LT group suggested that patients in the EC group may have been at higher operative risk because of their higher incidence of morphologically right ventricles, heterotaxy syndromes, worse atrioventricular valve regurgitation, and lower McGoon indices. Despite these poorer preoperative characteristics, patients within the EC group had comparable outcomes in terms of mortality or Fontan failure to patients within the LT group.

Most studies analyzing risk factors for outcomes after the Fontan operation have demonstrated that longer CPB times are associated with an increased risk of Fontan failure or mortality. 2,3,6 Our analysis confirms this finding. The multivariable analysis did not, however, suggest that the type of Fontan connection, use of fenestration, need for or duration of aortic crossclamping, or atrioventricular valve regurgitation were risk factors for death or Fontan failure. The potential avoidance or minimization of CPB with the EC approach infers that mortality may be improved after the modified Fontan operation. Whether performance of the EC technique with minimal or no CPB will in fact afford a better outcome is not proved by these data. Although such an approach may eliminate or minimize the factor that has repeatedly emerged as an important predictor of Fontan failure or mortality in most series, it is possible that features specific to that operation may emerge as risk factors for Fontan failure or mortality. The "off-pump" approach may bring in a new set of procedural risk factors unique to its application (for example, reperfusion injury of the isolated lung, variations in hemodynamics, or hepatic congestion).

Although approximately $20 \%$ of the patients in the EC group required an intracardiac procedure, aortic crossclamping can be completely avoided by completing intracardiac procedures at the time of bidirectional cavopulmonary anastomosis. The completion of associated intracardiac and extracardiac procedures at the time of the bidirectional cavopulmonary anastomosis may also reduce the duration of CPB at the time of Fontan completion.

The postoperative course of patients after the Fontan procedure is also significantly affected by the duration of CPB. By multivariable analysis, prolonged CPB time was the only independent predictor of ICU length of stay and need for prolonged ventilatory support. Although CPB times were comparable between groups, patients in the LT group had significantly longer stays in the ICU and required a longer duration of ventilatory support. The multivariable analysis showed $P$ values of .08 and .11 for LT Fontan connection as a predictor of prolonged ventilation or ICU length of stay, respectively, suggesting that there was a trend toward increased resource use with LT Fontan connection.

Another important finding from this analysis revolves around the issue of atrial arrhythmias after the Fontan operation. The incidence of atrial arrhythmias after the Fontan operation ranges from $10 \%$ to $40 \% .^{12-16}$ These arrhythmias include sinus node dysfunction (caused by injury of the sinus node or a disturbance of its blood supply), supraventricular tachycardias including junctional ectopic tachycardia, atrial ectopic tachycardia, and atrial flutter. ${ }^{15}$ The need for temporary pacing in the early postoperative period also ranges from $5 \%$ to $30 \%$, and an important number of patients will require permanent pacing. Gandhi and associates $^{15}$ have shown in an animal model that the proximity of the suture line within the LT Fontan connection to the crista terminalis affects the development of atrial flutter. In the current series, efforts were made to avoid the crista terminalis. The presence of extensive right atrial trabeculations, however, may require a shallow suture line along the crista terminalis to avoid baffle leaks. The EC avoids suture load- 
ing of the atrium, extensive atrial incisions, and manipulation or injury of the sinoatrial node. However, the performance of the bidirectional cavopulmonary anastomosis may in fact result in manipulation of the sinoatrial node or injury of its arterial supply such that the patient is at an increased risk for the development of sinoatrial node dysfunction. This analysis demonstrates that the LT Fontan connection is an independent predictor of early and midterm postoperative atrial arrhythmias including sinoatrial node dysfunction, supraventricular tachycardia, and need for temporary or permanent pacing.

Cohen and colleagues ${ }^{17}$ recently reported a prospective cohort study conducted to evaluate the incidence of sinus node dysfunction in patients having either a hemi-Fontan or bidirectional cavopulmonary anastomosis as a staging operation and subsequent LT Fontan or EC connection. The incidence of sinoatrial node dysfunction in either group was monitored by Holter monitor at hospital discharge. Twelve percent of the entire cohort had sinus node dysfunction after the Fontan operation. The incidence in the hemi-Fontan/LT group was $14 \%$ compared with $10 \%$ in the bidirectional cavopulmonary anastomosis/EC group. The authors conclude that there was no significant difference in the incidence of sinus node dysfunction in either group and that avoidance of surgery near the sinoatrial node had no discernible effect on the development of sinus node dysfunction.

These findings differ from ours for a number of reasons. First, we surveyed all patients for evidence of any atrial rhythm disturbance including sinus node dysfunction, supraventricular tachycardia, and any need for temporary pacing. Second, because Fontan hemodynamics are marginal in the early postoperative period and the instantaneous risk of death is highest in the first month after the operation, we did not limit the evaluation to one specific time point in the postoperative period. Rather, the medical records were examined for any atrial arrhythmia (regardless of duration) at any time point in the postoperative period.

The Fontan circulation is most vulnerable in the early postoperative period. ${ }^{1,2}$ Any impairment in cardiac output resulting from arrhythmia may compromise hemodynamics and risk failure of the Fontan circuit. Although use of the LT Fontan connection is an independent predictor of postoperative rhythm disturbances, patients in the LT group did not differ from the EC group in terms of mortality or Fontan failure. Indeed, the EC group may have been at higher risk on the basis of their preoperative characteristics. It may be difficult to demonstrate that a single improvement in postoperative course results in improved early survival, an outcome that is affected by a multitude of factors. The sum of small improvements ${ }^{18}$ in operative strategies and perioperative care (avoidance of myocardial ischemia, minimization of CPB and subsequent pulmonary vascular and parenchymal dysfunction, and reduction in postoperative arrhyth- mias) may translate into improved survival, rather than a single event or intervention.

Staging of the Fontan circulation continues to be an important issue, the impact of which has yet to be determined. We are moving toward the performance of the bidirectional cavopulmonary anastomosis or hemi-Fontan at an earlier age (3-6 months). There was a trend toward earlier median age at which the second-stage operation was performed in patients in the EC group ( 9 months) compared with those in the LT group (10 months). The age at which the Fontan operation was performed did not differ between the EC and LT groups. Because of its growth potential, the LT Fontan operation can generally be done at a younger age than the EC operation. Earlier unloading of the single ventricle may have an important effect on exercise performance and longevity of the ventricle. ${ }^{19}$

Fenestration use did not affect early survival, resource use, or chest tube drainage. We continue to favor its use because the presence of a fenestration may extend the margin of Fontan hemodynamic vulnerability. ${ }^{3,20}$ In our experience with followup catheterization at a median of 12 months after the Fontan operation, $40 \%$ of fenestrations closed spontaneously.

The EC does not have growth potential. In addition, the conduit is at risk for the development of obstruction caused by thrombus formation or the development of fibrosis, neointimal hyperplasia, and/or calcification. Use of an adult-sized conduit (20-22 mm) may avoid future reoperations and may accommodate flow rates necessary for exercise. This limits the use of the EC connection to patients of a minimum age, weight, and/or size. The LT Fontan is, therefore, preferentially indicated for the younger or smaller symptomatic child. A previous hemi-Fontan also favors use of the LT connection. From our data, patients receiving an EC connection have weights ranging from 9.3 to $35 \mathrm{~kg}$ with a median weight of $13.2 \mathrm{~kg}$. It is plausible that the minimum weight for an EC Fontan candidate should be around $15 \mathrm{~kg}$, because a 20- to $22-\mathrm{mm}$ conduit in a smaller child is relatively oversized and risks the formation of laminated thrombus in the Fontan circuit. Ultimately the fate of PTFE or homograft cavopulmonary conduits will be determined by longer clinical follow-up.

\section{References}

1. Fontan F, Kirklin JW, Fernandez G, Costa F, Naftel DC, Tritto F, et al. Outcome after a "perfect" Fontan operation. Circulation. 1990;81: 1520-36.

2. Kirklin JW, Barratt-Boyes BG. Tricuspid atresia and the Fontan operation. In: Kirklin JW, Barratt-Boyes BG, editors. Cardiac surgery, 2nd ed, volume 2. New York: Churchill Livingstone; 1993. p. 1055-104.

3. Gentles TL, Mayer JE Jr, Gavreau K, Newburger JW, Lock JE, Kupferschmid JP, et al. Fontan operation in five hundred consecutive patients: factors influencing early and late outcome. J Thorac Cardiovasc Surg. 1997;114:376-91.

4. Knott-Craig, Danielson GK, Schaff HV, Puga FJ, Weaver AL, Driscoll DD. The modified Fontan operation: an analysis of risk factors for early postoperative death or takedown in 702 consecutive patients from one institution. J Thorac Cardiovasc Surg. 1995;109:1237-43. 
5. Pizarro C, de Leval MR. Surgical variations and flow dynamics in cavopulmonary connections: a historical review. Pediatr Card Surg Annu Semin Thorac Cardiovasc Surg. 1998;1:53-9.

6. Petrossian E, Reddy VM, McElhinney DB, Akkersdijk GP, Moore P, Parry AJ, et al. Early results of the extracardiac conduit Fontan operation. J Thorac Cardiovasc Surg. 1999;117:688-96.

7. Marcelletti CF, Iorio FS, Abella RF. Late results of extracardiac Fontan repair. Pediatr Card Surg Annu Semin Thorac Cardiovasc Surg. 1999;2: 131-41.

8. Mayer JE Jr. Late outcome after the Fontan procedure. Pediatr Card Surg Annu Semin Thorac Cardiovasc Surg. 1998;1:5-8.

9. Stamm C, Friehs I, Mayer JE, Zurakowski D, Triedman JK, Moran $\mathrm{AM}$, et al. Long-term results of the lateral tunnel Fontan operation. $J$ Thorac Cardiovasc Surg. 2001;121:28-41.

10. Kaplan EL, Meier P. Nonparametric estimation from incomplete observations. J Am Stat Assoc. 1958;53:457-81.

11. Knott-Craig CJ, Julsrud PR, Schaff HV, Puga FJ, Danielson GK. Pulmonary artery size and clinical outcome after the modified Fontan operation. Ann Thorac Surg. 1993;55:646-51.

12. Gelatt M, Hamilton RM, McCrindle BW, Gow RM, Williams WG, Trusler GA, et al. Risk factors for atrial tachyarrhythmias after the Fontan operation. J Am Coll Cardiol. 1994;24:1735-41.

13. Cohen MI, Rhodes LA. Sinus node dysfunction and atrial tachycardia after the Fontan procedure: the scope of the problem. Pediatr Card Surg Annu Semin Thorac Cardiovasc Surg. 1998;1:41-51.

14. Shirai LK, Rosenthal DN, Reitz BA, Robbins RC, Dubin AM. Arrhythmias and thromboembolic complications after the extracardiac Fontan operation. J Thorac Cardiovasc Surg. 1998;115:499-505.

15. Gandhi SK, Bromberg BI, Rodefeld MD, Schuessler RB, Boineau JP, Cox JL, et al. Lateral tunnel suture line variation reduces atrial flutter after the modified Fontan operation. Ann Thorac Surg. 1996;61:1299-309.

16. Fishberger SB, Wernovsky G, Gentles TL, Gauvreau K, Burnett J, Mayer JE Jr, et al. Factors that influence the development of atrial flutter after the Fontan operation. J Thorac Cardiovasc Surg. 1997;113:80-6.

17. Cohen MI, Bridges ND, Gaynor JW, Hoffman TM, Wernovsky G, Vetter VL, et al. Modifications to the cavopulmonary anastomosis do not eliminate early sinus node dysfunction. J Thorac Cardiovasc Surg. 2000;120:891-900.

18. de Leval MR, Carthey J, Wright DJ, Farewell VT, Reason JT, all United Kingdom pediatric cardiac centers. Human factors and cardiac surgery: a multicenter study. J Thorac Cardiovasc Surg. 2000;119:661-72.

19. Mahle WT, Wernovsky G, Bridges ND, Linton AB, Paridon SM. Impact of early ventricular unloading on exercise performance in preadolescents with single ventricle Fontan physiology. J Am Coll Cardiol. 1999;34:1637-43.

20. Bridges ND. Fenestration of the Fontan baffle: benefits and complications Pediatr Card Surg Annu Semin Thorac Cardiovasc Surg. 1998;1:9-13.

\section{Bound volumes available to subscribers}

Bound volumes of The Journal of Thoracic and Cardiovascular Surgery are available to subscribers (only) for the 2001 issues from the Publisher, at a cost of $\$ 134.00$ for domestic, \$165.85 for Canadian, and \$155.00 for international subscribers for Vol 121 (January-June) and Vol 122 (July-December). Shipping charges are included. Each bound volume contains a subject and author index and all advertising is removed. Copies are shipped within 60 days after publication of the last issue of the volume. The binding is durable buckram with the Journal name, volume number, and year stamped in gold on the spine. Payment must accompany all orders. Contact Mosby, Subscription Customer Service, 6277 Sea Harbor Dr, Orlando, FL 32887, USA; phone 800-654-2452 or 407-345-4000.

Subscriptions must be in force to qualify. Bound volumes are not available in place of a regular Journal subscription. 